\title{
Organisationally relevant variables and Keyes's Mental Health ContinuUm Scale: An EXPlORATORY STUdy
}

\author{
Authors: \\ Deo J.W. Strümpfer ${ }^{1}$ \\ Anneli Hardy ${ }^{2}$ \\ Joan S. de Villiers ${ }^{3}$ \\ Susan Rigby ${ }^{3}$
}

\section{Affiliations:}

${ }^{1}$ Department of

Psychology, University of

Johannesburg, South

Africa

${ }^{2}$ Department of Statistics, University of Cape Town South Africa

${ }^{3}$ Department of Human

Resources Management,

University of

Johannesburg,

South Africa

\section{Correspondence to:}

Deo J.W. Strümpfer

e-mail:

deostr@gmail.com

Postal address:

PO Box 285, Stanford,

7210 , South Africa

\section{Keywords:}

flourishing; languishing; psychosocial health;

Keyes's Mental Health

Continuum Scale;

psychosocial illness

\section{Dates:}

Received: 31 Oct. 2008

Accepted: 14 July 2009

Published: 04 Sept. 2009

How to cite this article: Strümpfer, D.J.W., Hardy, A., De Villiers, J.S., \&

Rigby, S. (2009).

Organisationally relevant variables and Keyes's

Mental Health Continuum

Scale: An exploratory

study. SA Journal of

Industrial Psychology/SA

Tydskrif vir Bedryfsielkunde,

35(1), Art. \#763, 7 pages.

DOI: 10.4102/sajip.v35i1.763

\begin{abstract}
This article is available at: http://www.sajip.co.za
\end{abstract}

(C) 2009. The Authors. Licensee: OpenJournals Publishing. This work

is licensed under the

Creative Commons

Attribution License.

\section{ABSTRACT}

In an exploratory study on a sample of convenience $(n=165), 11$ self-report variables with presumed organisational relevance were related, as predictors, to the three subscores and summed score of the Keyes (2005a, 2005b; 2007) Mental Health Continuum Scale (long form). Keyes's scale was administered five to seven days after the first set of scales. The predictor scores were reduced to three factorial scores, labelled positive orientation, negative orientation and positive striving. When classified thus, the predictor variables showed significant and meaningful relationships with some or all of the Keyes subscores and the total score, although few reached medium effect sizes.

\section{INTRODUCTION}

How would one construe psychosocial health? In the not too distant past (and is it 'past' yet?), it meant the absence of psychosocial pathology; it was there or it was not. Subsequently, psychosocial illness and health came to be viewed along a continuum, placing complete illness at one extreme and complete health at the other. Antonovsky $(1979 ; 1987)$ developed an example: a bipolar continuum of dis-ease-health ease. More recently, questions arose about the possibility of two separate continua. For one, Keyes (e.g., 2002; 2005a; 2007) proposed - and found empirical support for - a continuum representing mental ill-health and another representing mental health.

Keyes's measure of the mental health continuum is the criterion in this paper. The continuum stretches between flourishing and languishing. In Keyes's (2007, p. 396) view, 'mental health, like mental illness, is a syndrome of symptoms of subjective well-being. Complete mental health consists of the absence of diagnosable mental disorder and the presence of flourishing. Purely flourishing individuals experience high levels of emotional well-being and function well both psychologically and socially; they show enthusiasm for life and are actively and productively involved. Pure languishing, on the other hand, manifests in individuals' being mentally unhealthy (though without diagnosable mental disorder), with low levels of emotional, psychological and social well-being. They experience emptiness, stagnation and quiet despair; they 'describe themselves and life as "hollow", "empty", "a shell", and "void"' (Keyes, 2002, p. 210). Keyes $(2003$, p. 296) noted that such a condition may be present even among, for example, women who have all the 'trappings of success - good marriages, great children, good jobs, and nice homes in good neighborhoods'. Though they may be towards the bottom end of the psychosocial well-being continuum, languishers would still be functioning in psychological and social contexts to an extent that cannot be described as mental illness. They are thus neither mentally ill nor mentally healthy.

Keyes (2005a) construed mental illness in terms of psychiatric morbidity and operationalised it by means of a structured interview measure based on the Diagnostic and Statistical Manual (DSM). The continuum of mental health was operationalised by means of self-descriptive scales on emotional well-being, psychological well-being and social well-being. Using data from the MacArthur Foundation National Study of Successful Midlife Development, Keyes compared confirmatory factor models that tested four different theories of the latent structure of the measures of mental health and mental illness. The best-fitting model was a two-factor (orthogonal) model representing the independence of the two conditions, from which Keyes concluded that mental illness and mental health constituted two distinct but significantly negatively correlated axes (-0.53: $28 \%$ of common variance). He also used the presence of four mental illness conditions, viz. a major depressive episode, generalised anxiety disorder, panic disorder and alcohol dependence, as well as their comorbidity (two to four disorders during the past 12 months) as criteria; flourishing individuals were at the lowest risk of any of these five conditions. In addition, the languishing-flourishing continuum was related to occupational and psychosocial malfunctioning, which was lowest among adults with complete mental health.

Adults who were diagnosed as completely mentally healthy functioned superior to all others in terms of the fewest workdays missed, fewest half-day or less cutbacks of work, lowest level of health limitations of activities of daily living, the fewest chronic physical diseases and conditions, the lowest health care utilisation, and the highest levels of psychosocial functioning.

(Keyes, 2007, p. 100)

This group was, furthermore, characterised by the lowest level of perceived helplessness, the highest level of functional goals, the highest level of self-reported resilience and the highest level of intimacy. They generally functioned better than moderately mentally healthy adults, who, in turn, functioned better than purely languishing adults.

A confirmatory factor analysis on the short form of Keyes's questionnaire by Keyes et al. (2008) supported the hypothesised two-continuum model of mental health and mental illness found in the USA in a Setswana-speaking South African sample. The study also replicated the three-factor structure of emotional, psychological and social well-being found in US samples. Confirmatory factor analyses by Robitschek and Keyes (2009) also supported the three-factor model in two samples of US college students. 
Mental illness, languishing and flourishing are not stable or permanent conditions. It could, therefore, be hypothesised that people could move up and down along the continua due to both subjective and external conditions. With respect to the first continuum, people who have previously been well become mentally ill, and people recover from a pure form of a mental illness to an absence of such illness. Along the other continuum, people could theoretically move from pure languishing to pure flourishing or vice versa.

It could be surmised that a variety of personal and social experiences are behind the moving upwards or downwards along the languishing-flourishing continuum. In a work and organisational context, self-directed work experiences (e.g. Kohn \& Schooler, 1982) and participation in socially valued decision making (Antonovsky, 1987) as well as coaching, some forms of training and some small-group experiences could all contribute to growth towards flourishing. Similarly, a range of untoward experiences in the workplace could result in downward movement, for example negative work experiences from which there is no escape, physical violence, injury, disablement, discrimination and unemployment; these processes are not, however, inevitably irreversible - eventually a person could start climbing back up again. It is, for example, not uncommon for persons who experienced a traumatic retrenchment that the experience eventually turned into a 'kick start' towards a successful new career.

Keyes (2005a) reported on mental health measured by his methodology and human resource criteria, such as absenteeism. To explore the methodology further, the present study expanded in that direction by relating a variety of psychological variables that were presumed to be organisationally relevant to Keyes's psychosocial well-being measure. It was an exploratory study and measures were chosen to represent diverse characteristics in terms of the constructs operationalised as well as in terms of their reported reliability and validity information. The first group of variables was operationalised by means of what could be described as personally linked measures: They allow one to describe how one feels about one's work and how one perceives oneself as a working person. The second group was operationalised by means of what could be described as organisation-linked measures: They represent one's reactions towards the organisation or towards how the organisation is perceived to function. This grouping is not without overlap. All of these measures, like that of Keyes, provide self-reports.

The research question was whether the chosen measures could predict Keyes's psychosocial well-being scores obtained five to seven days later.

\section{Research procedure}

\section{RESEARCH DESIGN}

Data were collected by the third and fourth authors. They briefed human resource managers in various companies and obtained their cooperation in identifying potential participants who fulfilled the selection requirements. These managers then informed persons about the study, explained its purpose, indicated that participation was voluntary and assured them of confidentiality. If they were willing to participate, they were handed the first paper-and-pencil questionnaire, which started off by repeating information on the study, voluntary participation and confidentiality. It contained the scales measuring the organisationally relevant variables. The second questionnaire contained the Keyes (2005a) Mental Health Continuum Scale (long form). It was administered to the same participants five to seven days after the first one had been collected, in an attempt to reduce the effect of random error variance that results from concurrent administration The aim was also to obtain a short-term prospective criterion, thus perhaps reducing the plausibility of a reverse direction of causality.

\section{Research participants}

A sample of employees was obtained from a variety of companies in the southern Cape and Gauteng parts of the country; the sample was not stratified or random. Participants all had to be permanently employed in organisations with at least six employees, between the ages of 18 and about 68 and (in view of the reading requirement) with an educational level of Grade 12 and above. Of the sample of 165 persons, $90(54.5 \%)$ were female. The participants' mother tongue was Afrikaans 84 (50.9\%), English 65 (39.4\%) and an African language 15 (9.1\%) (of which 12 , or $7.3 \%$, were isiXhosa speakers). Approximately half of the organisations represented were small to medium size and half of them large, according to participants' estimates.

\section{Measuring instruments Organisationally relevant measures}

Questionnaire 1 contained six personally linked scales (example items appear in parentheses). 'Overall Job Satisfaction' was measured by Eisenberger, Cummings, Armeli and Lynch's (1997) scale ('All in all, I am very satisfied with my current job'), which consists of four items from Quinn and Sheppard's (1974) Job Satisfaction Index; the authors reported a Cronbach alpha of 0.85 . In an attempt to reduce response set, one item of this scale was reversed by adding 'not'. 'Job-related Self-efficacy' was measured by Jones's (1986) eight-item scale ('My job is well within the scope of my abilities'), for which the author reported an alpha of 0.71 ; items were edited from describing a newcomer, as in the original, to describing an incumbent. 'Performance (or 'Approach') Orientation' ('I feel most successful in my job when I am the best') and 'Mastery Orientation' ('I feel most successful in my job when I improve on particular aspects') were measured by Van Yperen and Janssen's (2002) scales, for both of which the authors reported an alpha of 0.86 ; the first scale contains eight items and the last three items of Mastery Orientation were deleted to reduce the number of items to eight too. 'Proactive Personality' ('I excel at identifying opportunities') was measured by Bateman and Crant's (1993) and Crant's (2000) 10-item scale; Bateman and Crant reported three reliability estimates from 0.87 to 0.89 . 'Fatigue' ('At the end of a working day, I feel really fatigued') was measured by Van Yperen and Janssen's (2002) English translation of an 11-item Dutch scale; the authors reported an alpha of 0.90 .

Questionnaire 1 also contained five organisationally linked scales. Oreg's (2003) 'Resistance to Change' scale ('I generally consider change to be a negative thing') contains 18 items, with an alpha of 0.92; four factors are represented and the items of these were rearranged to alternate the factors. Three organisational commitment scales by Allen and Meyer (1990) were used. 'Affective Commitment' ('This organisation has a great deal of meaning for me') and 'Normative Commitment' ('I think that people these days move from company to company too often') were each measured by eight items; Allen and Meyer (1990) reported alphas of 0.86 and 0.73 for these two scales, respectively. 'Continuance Commitment' ('Right now, staying with my organisation is a matter of necessity as much as desire') reflects the employee's considerations about the costs of leaving; Allen and Meyer (1990) reported an alpha of 0.82 for this scale. In the present study Continuance Commitment was measured by five items (see explanation in Results section). The eight-item short form of the Perceived Organisational Support scale ('My organisation really cares about my well-being') of Eisenberger et al. (1997) was used; the authors reported an alpha of 0.90 .

In assembling Questionnaire 1, the response scales of the authors were retained but the sequence of response formats was varied systematically: Semantic differentials with just the end points labelled, five- and seven-point Likert scales with anchors described differently for different scales, numbered responses (five and seven) to be circled at the end of items with anchors described differently for different scales and numbered responses to be written in spaces at the end of items. The 
TABLE 1

Descriptive statistics and coefficients alpha of variables

\begin{tabular}{|c|c|c|c|c|c|c|}
\hline VARIABLE & n OF ITEMS & MEAN & SD & MIN. & MAX. & ALPHA \\
\hline \multicolumn{7}{|l|}{ Personally linked } \\
\hline Job Satisfaction & 4 & 20.46 & 4.53 & 5 & 28 & 0.66 \\
\hline Job-related Self-efficacy & 6 & 31.90 & 4.91 & 13 & 42 & 0.63 \\
\hline Performance Orientation & 8 & 26.91 & 6.86 & 9 & 40 & 0.88 \\
\hline Mastery Orientation & 8 & 35.74 & 3.74 & 25 & 40 & 0.86 \\
\hline Proactive Personality & 10 & 54.63 & 8.58 & 34 & 70 & 0.88 \\
\hline \multicolumn{7}{|l|}{ Organisationally linked } \\
\hline Resistance to Change & 18 & 57.80 & 11.91 & 28 & 53 & 0.79 \\
\hline Affective Commitment & 8 & 36.68 & 8.69 & 10 & 55 & 0.74 \\
\hline Continuance Commitment & 5 & 22.71 & 6.32 & 5 & 35 & 0.66 \\
\hline Normative Commitment & 8 & 34.71 & 8.79 & 12 & 54 & 0.73 \\
\hline Perceived Org. Support & 8 & 38.34 & 10.13 & 8 & 56 & 0.88 \\
\hline \multicolumn{7}{|l|}{ Criteria } \\
\hline Emotional Well-being & 6 & 19.83 & 4.02 & 7 & 30 & 0.89 \\
\hline Psychological Well-being & 18 & 98.69 & 11.90 & 60 & 125 & 0.73 \\
\hline Social Well-being & 15 & 72.94 & 12.79 & 39 & 101 & 0.79 \\
\hline TOTAL MENTAL HEALTH $^{A}$ & 40 & 0.01 & 2.17 & -5.84 & 4.79 & - \\
\hline
\end{tabular}

a Sum of $Z$ scores on first three criterion scores

purpose was to avoid response sets by requiring participants to shift between different formats.

\section{Psychosocial well-being}

Keyes's (2002; 2005a) Mental Health Continuum Scale contains three components. The first section, Emotional Well-being, has two components. The first is measured by six items that enquire, on a five-point scale, how much of the time during the past 30 days an individual felt cheerful, in good spirits, extremely happy, calm and peaceful, satisfied and full of life. Keyes (2002) reported an alpha of 0.91 for this component. The scores on the six items are averaged to obtain a 'symptom' score. The second component is a single item on avowed quality of life: 'Using a scale from 0 to 10 , where 0 means "the worst possible life overall" and 10 means "the best possible life overall", how would you rate your life overall these days?' These two components are each standardised and then summed to obtain the Emotional Well-being score.

The second section of the questionnaire contains an 18-item form of Ryff's (1989; 2001) and Ryff and Keyes's (1995) Psychological Well-being ${ }^{1}$ measure, divided into six scales, each represented by three items: 'self-acceptance' ('I like most parts of my personality'), 'positive relations' with others ('People would describe me as a giving person, willing to share my time with others'), 'personal growth' ('For me, life has been a continual process of learning, changing, and growth'), 'purpose in life' ('Some people wander aimlessly through life, but I am not one of them'), 'environmental mastery' ('In general, I feel I am in charge of the situation in which I live') and 'autonomy' ('I have confidence in my opinions, even if they are contrary to the general consensus').

The third section contains Keyes's (1998) 15-item measure of 'Social well-being', which operationalises how much individuals see themselves thriving in their public, social life. The five three-item scales are 'social coherence' ('I try to think about and understand what could happen next in our country'), 'social integration' ('I feel close to other people in my community'), 'social-acceptance' ('I believe that people are kind'), social contribution ('I have something valuable to give

1.Juxtaposing 'emotional' and 'psychological' is somewhat confusing, since the latter could embrace the former. In various publications, Keyes equated 'emotional wellbeing' and 'positive affect', which is less confusing but does not juxtapose the three kinds of well-being. the world') and 'social actualisation' ('The world is becoming a better place for everyone').

The Psychological and Social Well-being scales are responded to on a seven-point Disagree-Agree scale. Ryff and Keyes (1995) and Keyes (1998), respectively, reported alphas of 0.81 for both the Psychological and Social Well-being scales. The three scores were investigated separately and a total score (Total Mental Health) was obtained by summing their standardised scores. ${ }^{2}$

\section{Statistical analysis}

The properties of the obtained scores were examined through descriptive statistics. Alpha coefficients were calculated and scales were examined by means of factor analysis where appropriate. Measures were intercorrelated and the correlations were finally assessed in terms of their effect sizes. Scores on the Keyes scales were factor analysed, as were those on the 11 organisationally relevant scales. Factorial scores were calculated to represent the latter group; these were intercorrelated with the three scores of the Keyes scales and the sum of their standardised scores.

\section{RESULTS}

Table 1 presents descriptive data and coefficients alpha for the different measures used. An initial item analysis indicated an unacceptably low coefficient alpha for the Job-related Selfefficacy scale; two items ('My job is well within the scope of my abilities'; 'Professionally speaking, my job exactly satisfies my expectations of myself') showed negative corrected itemtotal correlations, which reduced its coefficient alpha to 0.49 . When these items were deleted, the alpha increased to 0.63 ; this is rather low but, according to Clark and Watson (1995), still acceptable.

McGee and Ford (1987) as well as Hackett, Bycio and Hausdorf (1994) concluded that Continuance Commitment should be divided into High Sacrifice and Low Alternatives scales, each containing three items. Item analyses of the present data showed these subscales to have coefficients alpha of, respectively, 0.56

2.In order to make his mental health data comparable to his mental illness data, which were in DSM format, Keyes's (e.g., 2004, 2005a, 2007) diagnostic scheme also used a categorical approach with respect to psychosocial well-being: The prevalence a categorical approach with respect to psychosocial well-being. The prevalence of items in the categories of pure languishing, moderately mentally healhy and completely mentally healthy. Since categorisation reduces the amount of information and since there was no need to do so, the present study used only the continuous measures. 
TABLE 2

Intercorrelations of all variables, with levels of statistical and practical significance

\begin{tabular}{|c|c|c|c|c|c|c|c|c|c|c|c|c|c|c|c|c|c|}
\hline VARIABLE & & 1. & 2. & 3. & 4. & 5. & 6. & 7. & 8. & 9. & 10. & 11. & 12. & 13. & 14. & 15. & 16. \\
\hline 1. Age & $r$ & & & & & & & & & & & & & & & & \\
\hline 2. Education & $\begin{array}{l}r \\
p\end{array}$ & $\begin{array}{l}-0.21 \\
0.006\end{array}$ & & & & & & & & & & & & & & & \\
\hline 3. Job Satisfaction & $r$ & -0.03 & 0.04 & & & & & & & & & & & & & & \\
\hline $\begin{array}{l}\text { 4. Job-related } \\
\text { Self-efficacy }\end{array}$ & $r$ & 0.11 & 0.06 & -0.03 & & & & & & & & & & & & & \\
\hline $\begin{array}{l}\text { 5. Performance } \\
\text { Orientation }\end{array}$ & $r$ & -0.08 & -0.1 & 0.05 & 0.07 & & & & & & & & & & & & \\
\hline $\begin{array}{l}\text { 6. Mastery } \\
\text { Orientation }\end{array}$ & $\begin{array}{l}r \\
p\end{array}$ & $\begin{array}{l}-0.19 \\
0.016\end{array}$ & -0.03 & $\begin{array}{r}0.20 \\
0.012\end{array}$ & $\begin{array}{r}0.21 \\
0.007\end{array}$ & $\begin{array}{r}0.21 \\
0.009\end{array}$ & & & & & & & & & & & \\
\hline $\begin{array}{l}\text { 7. Proactive } \\
\text { Personality }\end{array}$ & $\begin{array}{l}r \\
p\end{array}$ & -0.05 & -0.12 & $\begin{array}{r}0.16 \\
0.040\end{array}$ & $\begin{array}{r}0.24 \\
0.002\end{array}$ & $\begin{array}{r}0.26 \\
0.001\end{array}$ & $\begin{array}{r}0.27 \\
0.000\end{array}$ & & & & & & & & & & \\
\hline 8. Fatigue & $\begin{array}{l}r \\
p\end{array}$ & -0.03 & 0.09 & -0.12 & -0.05 & $\begin{array}{r}0.23 \\
0.004\end{array}$ & 0.06 & 0.04 & & & & & & & & & \\
\hline $\begin{array}{l}\text { 9. Resistance to } \\
\text { Change }\end{array}$ & $\begin{array}{l}r \\
p\end{array}$ & 0.03 & $\begin{array}{l}-0.33 \\
0.000\end{array}$ & 0.02 & $\begin{array}{l}-0.25 \\
0.001\end{array}$ & $\begin{array}{r}0.23 \\
0.004\end{array}$ & -0.11 & $\begin{array}{l}-0.18 \\
0.023\end{array}$ & $\begin{array}{r}0.16 \\
0.042\end{array}$ & & & & & & & & \\
\hline $\begin{array}{l}\text { 10. Affective } \\
\text { Commitment }\end{array}$ & $\begin{array}{l}r \\
p\end{array}$ & 0.13 & -0.07 & $\begin{array}{r}\mathbf{0 . 5 6} \\
0.000\end{array}$ & -0.05 & -0.01 & $\begin{array}{r}0.18 \\
0.023\end{array}$ & 0.12 & 0 & 0.06 & & & & & & & \\
\hline $\begin{array}{l}\text { 11. Continuance } \\
\text { Commitment }\end{array}$ & $\begin{array}{l}r \\
p\end{array}$ & $\begin{array}{r}0.21 \\
0.006\end{array}$ & $\begin{array}{r}-0.18 \\
0.020\end{array}$ & 0.10 & -0.08 & $\begin{array}{r}0.18 \\
0.021\end{array}$ & -0.04 & 0.04 & 0.09 & $\begin{array}{r}\mathbf{0 . 3 6} \\
0.000\end{array}$ & 0.11 & & & & & & \\
\hline $\begin{array}{l}\text { 12. Normative } \\
\text { Commitment }\end{array}$ & $\begin{array}{l}r \\
p\end{array}$ & 0.10 & $\begin{array}{l}-0.36 \\
0.000\end{array}$ & $\begin{array}{r}0.23 \\
0.004\end{array}$ & -0.09 & 0.09 & 0.15 & $\begin{array}{r}0.17 \\
0.026\end{array}$ & 0.01 & $\begin{array}{r}0.22 \\
0.004\end{array}$ & $\begin{array}{r}\mathbf{0 . 5 4} \\
0.000\end{array}$ & $\begin{array}{r}0.24 \\
0.002\end{array}$ & & & & & \\
\hline $\begin{array}{l}\text { 13. Organisational } \\
\text { Support }\end{array}$ & $\begin{array}{l}r \\
p\end{array}$ & -0.03 & 0.04 & $\begin{array}{r}\mathbf{0 . 6 1} \\
0.000\end{array}$ & -0.11 & -0.05 & $\begin{array}{r}0.23 \\
0.004\end{array}$ & 0.03 & -0.10 & 0.06 & $\begin{array}{r}\mathbf{0 . 5 6} \\
0.000\end{array}$ & 0.07 & $\begin{array}{l}-0.32 \\
0.000\end{array}$ & & & & \\
\hline $\begin{array}{l}\text { 14. Emotional } \\
\text { Well-being }\end{array}$ & $\begin{array}{l}r \\
p\end{array}$ & 0.02 & -0.16 & $\begin{array}{r}0.22 \\
0.005\end{array}$ & -0.02 & 0.15 & 0.07 & 0.10 & $\begin{array}{l}-0.19 \\
0.015\end{array}$ & 0.01 & $\begin{array}{r}0.21 \\
0.006\end{array}$ & 0.01 & 0.14 & $\begin{array}{r}0.22 \\
0.005\end{array}$ & & & \\
\hline $\begin{array}{l}\text { 15. Psychological } \\
\text { Well-being }\end{array}$ & $\begin{array}{l}r \\
p\end{array}$ & -0.02 & $\begin{array}{r}0.21 \\
0.008\end{array}$ & $\begin{array}{r}0.22 \\
0.005\end{array}$ & 0.10 & -0.14 & $\begin{array}{r}0.19 \\
0.019\end{array}$ & $\begin{array}{r}0.20 \\
0.011\end{array}$ & $\begin{array}{l}-0.23 \\
0.003\end{array}$ & $\begin{array}{l}-0.35 \\
0.000\end{array}$ & 0.13 & $\begin{array}{l}-0.20 \\
0.010\end{array}$ & -0.03 & 0.15 & $\begin{array}{r}0.21 \\
0.008\end{array}$ & & \\
\hline $\begin{array}{l}\text { 16. Social } \\
\text { Well-being }\end{array}$ & $\begin{array}{l}r \\
p\end{array}$ & 0.11 & 0.01 & $\begin{array}{r}0.19 \\
0.017\end{array}$ & 0.07 & $\begin{array}{l}-0.24 \\
0.003\end{array}$ & -0.08 & 0.14 & $\begin{array}{l}-0.19 \\
0.016\end{array}$ & $\begin{array}{l}-0.22 \\
0.005\end{array}$ & 0.15 & $\begin{array}{l}-0.18 \\
0.020\end{array}$ & 0.09 & $\begin{array}{r}0.20 \\
0.014\end{array}$ & $\begin{array}{r}0.22 \\
0.006\end{array}$ & $\begin{array}{r}\mathbf{0 . 4 1} \\
0.000\end{array}$ & \\
\hline $\begin{array}{l}\text { 17. Sum Z } \\
14,15,16\end{array}$ & $\begin{array}{l}r \\
p\end{array}$ & 0.04 & 0.03 & $\begin{array}{r}0.29 \\
0.000\end{array}$ & 0.08 & -0.09 & 0.10 & $\begin{array}{r}0.21 \\
0.008\end{array}$ & $\begin{array}{l}-0.27 \\
0.001\end{array}$ & $\begin{array}{l}-0.26 \\
0.001\end{array}$ & $\begin{array}{r}0.23 \\
0.004\end{array}$ & -0.13 & 0.08 & $\begin{array}{r}0.26 \\
0.001\end{array}$ & $\begin{array}{r}\mathbf{0 . 6 6} \\
0.000\end{array}$ & $\begin{array}{r}\mathbf{0 . 7 5} \\
0.000\end{array}$ & $\begin{array}{r}\mathbf{0 . 7 6} \\
0.000\end{array}$ \\
\hline
\end{tabular}

Note 1: $p$ values 2-tailed

Note 2: Effect size $\approx 0.10=$ Small, ES $\approx 0.30=$ Medium, ES $\approx 0.50=$ Large (Cohen, 1988); rs with medium and large effect sizes in bold

TABLE 3

Factor analysis of predictor variables

\begin{tabular}{lrrr}
\hline VARIABLE & FACTOR 1 & FACTOR 2 & FACTOR 3 \\
\hline Affective Commitment & $\mathbf{0 . 8 1}$ & 0.00 & 0.03 \\
Perceived Org. Support & $\mathbf{0 . 7 8}$ & -0.12 & -0.02 \\
Overall Job Satisfaction & $\mathbf{0 . 7 2}$ & -0.09 & 0.11 \\
Normative Commitment & $\mathbf{0 . 5 3}$ & 0.22 & 0.00 \\
Resistance to Change & 0.09 & $\mathbf{0 . 6 4}$ & -0.34 \\
Performance Orientation & -0.06 & $\mathbf{0 . 5 2}$ & 0.36 \\
Continuance Commitment & 0.13 & $\mathbf{0 . 4 2}$ & -0.08 \\
Fatigue & -0.12 & $\mathbf{0 . 4 0}$ & 0.06 \\
Proactive Personality & 0.10 & 0.09 & $\mathbf{0 . 5 8}$ \\
Mastery Orientation & 0.21 & 0.02 & $\mathbf{0 . 4 8}$ \\
Job-related Self-efficacy & -0.14 & -0.14 & $\mathbf{0 . 4 7}$ \\
\hline
\end{tabular}

Note: Principal axis factoring, oblimin rotation with Kaiser normalisation

and 0.41; hence they were combined into a single Continuance Commitment scale. However, subjected to a further item analysis, the combined scale still showed a coefficient alpha of 0.64. An item ('I enjoy discussing my organisation with people outside it') showed an item-total correlation of 0.20 , and deleting it resulted in a marginally better alpha of 0.66 ; the present Continuance Commitment scale thus contained five items. All other coefficients alpha ranged between 0.73 and 0.89 .
With respect to biographical variables, only in the case of Mastery Orientation did a two-tailed $t$ test for independent samples show a significant difference between female and male subsamples (female $\mathrm{M}=36.34, \mathrm{~s}=3.53$; male $\mathrm{M}=35.04, \mathrm{~s}=3.89$ ): $\mathrm{t}(89,74)=2.24(95 \% \mathrm{CI}=0.15$ to $2.44 ; \mathrm{d}=0.351)$. This difference in a single instance was not considered large enough to warrant separate analyses for gender differences in all main results.

Table 2 presents the correlations between all of the variables as well as their levels of statistical and practical significance (effect size), in terms of Cohen's (1988) suggestions. According to Cohen (p. 91, Table 3.3.4), with $\mathrm{n}=160$ and $\alpha=0.01$ for a twotailed test, the power of $r=0.30$ is 0.90 and of $r=0.50$ is greater than 0.995. Correlation coefficients of less than 0.30 were not marked in Table 2 but only those with medium to large effect sizes. When an effect size is small, the finding concerned probably requires replication; a medium effect size could be of practical significance, whereas a large effect size is considered to be of practical significance.

Table 3 presents the results of factor analysing the 11 personally and organisationally linked variables together. Three initial eigenvalues larger than one were found and indicated that three factors could explain $55.46 \%$ of the variance. Table 3 contains the obliquely rotated pattern matrix. The correlations between the factors were $1-2=0.11,1-3=0.03$ and $2-3=0.00$. Factorial scales were constructed to measure each of the three factors.

A principal axis factor analysis of the three components of Keyes's (2005a) measure of psychosocial well-being produced 
TABLE 4

Correlations between factor scores of organisationally relevant variables and Keyes's scores

\begin{tabular}{lcrrrr}
\hline $\begin{array}{l}\text { FACTOR } \\
\text { SCORE }\end{array}$ & \multicolumn{2}{c}{$\begin{array}{c}\text { EMOTIONAL } \\
\text { WELL-BEING }\end{array}$} & $\begin{array}{r}\text { PSCHOLOGICAL } \\
\text { WELL-BEING }\end{array}$ & $\begin{array}{r}\text { SOCIAL } \\
\text { WELL-BEING }\end{array}$ & $\begin{array}{r}\text { TOTAL } \\
\text { MENTAL } \\
\text { HEALTH }\end{array}$ \\
\hline Positive & $r$ & 0.29 & 0.13 & 0.19 & 0.28 \\
Orientation & $p$ & 0.000 & & 0.015 & 0.000 \\
Negative & $r$ & -0.05 & -0.31 & -0.33 & -0.32 \\
Orientation & $p$ & & 0.000 & 0.000 & 0.000 \\
Positive & $r$ & 0.11 & 0.23 & 0.10 & 0.19 \\
Striving & $p$ & & 0.003 & & 0.014 \\
\hline
\end{tabular}

a single factor that explained $52.60 \%$ of the total variance. The loadings were Social Well-being 0.65, Psychological Well-being 0.64 and Emotional Well-being 0.34 . $^{3}$

The factorial scales that represented the personally and organisationally linked variables were correlated with the three components of Keyes's measure and the sum of their Z scores (to represent the single factor reported above). These results are shown in Table 4.

\section{DISCUSSION}

In an exploratory study on a sample of convenience $(n=165)$ self-report variables with presumed organisational relevance were related, as predictors, to Keyes's Mental Health Continuum Scale (long form). The latter measure was administered five to seven days after the first set of scales; it provided three subscores and a summed score that represent criteria of psychosocial well-being. The predictor scores were reduced to three factorial scores.

The correlation coefficients between the separate organisationally relevant variables and the psychosocial wellbeing scores are not being discussed, since the factors reported in Table 3 were subsequently correlated with the criterion variables. Nevertheless, the rows of correlations relating these predictor variables to the three components of Keyes's measure and their sum contain enough significant coefficients (though with low effect sizes) to have warranted the further investigation. The correlation between Resistance to Change and Psychological Well-being is high enough (-0.35) to have a medium effect size. It implies that persons who are high on Psychological Well-being are likely to be open to change, an important orientation in a world where change is an everflowing, ever-present part of reality (McMillan, 2004). It should be noted that the last three coefficients in Table 2 are part-whole correlations. Age shows a marginally significant negative correlation with Mastery Orientation (the older the participant, the less likely to be mastery orientated) and another positive one with Continuance Commitment (the older the person, the more likely the commitment to stay, a finding also reported by Hackett et al., 1994). Age and educational level show the to-be-expected marginally significant positive relationship. Educational level correlates significantly and negatively with Resistance to Change and Normative Commitment; in other words, the more educated a person is, the less resistance to change and the less feeling of an obligation to stay the person experiences (the latter finding was also reported by, e.g., Allen and Meyer (1990) and Iverson and Buttigieg (1999)).

Turning to the factor analysis of the organisationally relevant variables in Table 3, Factor 1 could be interpreted as indicating a

3.Keyes (2005b) reported confirmatory factor analysis findings that a three-factor model of the psychosocial well-being measure was the most tenable of models to fit the data. In a personal communication (25 September 2007) he commented on a 14-item short form that it included three emotional well-being items 'so that I could identify confirmatory factor models that tested the structure... (confirmatory models ( require at least three indice analysis could not be performed. Using the three component scales separately, nevertheless, served a similar purpose. positive orientation. The measures that loaded on this factor all convey an impression of being positive towards the organisation and the job. Affective Commitment represents an emotional attachment, meaning that the employee enjoys membership of the organisation, identifies with it and is involved in it; Normative Commitment represents an employee's internalised feeling of obligation to remain with the organisation and be involved in meeting its interests and goals (Allen \& Meyer, 1990; Hackett et al., 1994). Perceived Organisational Support represents 'a general perception concerning the degree to which the organization values [employees'] contributions and cares about their well-being' (Eisenberger et al., 1997, p. 812; also Lynch, Eisenberger \& Armeli, 1999). Overall Job Satisfaction is influenced by the favorableness of job conditions, largely independent of whether those conditions resulted from the employer's free choice' (Eisenberger et al., 1997, p. 814).

Factor 2 (Table 3) reflects what could be viewed as a negative orientation. The measures that loaded on this factor seem to reflect an overall negative, corroding mindset of rejecting change, a superior attitude towards coworkers, a feeling of having a tiresome job, yet perhaps a feeling of not being able to escape. Considering the four factors found in Resistance to Change (Oreg, 2003), viz. routine seeking, emotional reaction, short-term focus and cognitive rigidity, it clearly has a negative connotation. Van Yperen and Janssen (2002, p. 1161) described Performance Orientation as reflecting 'an individual's having the goal of establishing his or her superiority over others', that is, a competitive and ascendant attitude. As indicated above, Continuance Commitment contains negative considerations of not wanting to change on account of too high sacrifice and/or too low alternatives, in other words, a cost-induced commitment. Fatigue provides an indication of how fatigued employees feel at the end of a workday and their need to recover.

Factor 3 (Table 3) could be interpreted as reflecting a positive striving. Overall, the scales that loaded on this factor seem to project an image of proactive functioning, of striving to perform competently and of a self-efficacious belief in one's capability of striving positively. Bateman and Crant's (1993) Proactive Personality scale describes a person who effects environmental change by identifying opportunities and acting on them, showing initiative, taking action and persevering. Van Yperen and Jansen (2002) viewed Mastery Orientation as a mindset whereby an individual pursues development of competence, gaining skill and doing his/her best. In developing his Job-related Self-efficacy scale, Jones (1986) quoted Bandura (1977, p. 192), who wrote that self-efficacy consists of people's expectations that 'they can successfully execute the behavior required to produce the outcome'; in the case of Jones's scale, this implies mastery of job and organisational requirements (the low internal consistency of the scale should, however, be kept in mind).

It is clear that the initial classification of the organisationally relevant variables as psychologically or organisationally linked was not meaningful, in view of the presumed psychological constructs they represented. Subsequent factor analysis classified them differently.

The correlations of the factorial scales with the three components of Keyes's measure and the sum of their $\mathrm{Z}$ scores, reported in Table 4, present the concluding validation information of this study. They tend to provide an affirmative answer to the research question: Could the chosen measures predict Keyes's psychosocial well-being scores obtained five to seven days later? The positive orientation factor correlated significantly with Keyes's Emotional Well-being, Social Wellbeing and Total Mental Health. The negative orientation factor, in turn, correlated significantly and negatively with both Keyes's Psychological and Social Well-being and with Total Mental Health; these were, however, the only instances where the correlations were high enough to be of medium effect size. 
Lastly, the positive striving factor showed correlations with Keyes's Psychological Well-being and Total Mental Health. Most important are the consistently significant correlations of all three factor scores with Total Mental Health.

\section{Conclusion}

The reported findings tend to signify that when classified in terms of their construct validity - as positive orientation, negative orientation and positive striving - the presumed organisationally relevant variables selected for this study showed meaningful relationships to Keyes's Mental Health Continuum Scale (long form). Each of their factorial scores showed significant correlations with some or all of the three Keyes components and the Total Mental Health score, although few reached medium effect size. Although the five-to-sevendays lapse between the administration of questionnaires 1 and 2 was rather short, it also held a marginal promise of predictive validity.

These findings (and to some extent, the correlations of the separate scales with Keyes's measure in Table 2) suggest that further research to investigate the nomological net of the languishing-flourishing continuum would be warranted. Since the number of organisation-related variables was small - just a tiny selection from a vast pool - further study using different variables chosen on theoretical grounds seems worthwhile. Relating 'hard', real-life organisational variables, such as those reported by Keyes and Magyar-Moe (2003), to Keyes's measure could also evaluate its potential utility as an instrument in an organisational context.

Keyes's measure used in the present study is not the final word on measurement in this area; he noted that some may think the scheme he presented to be 'crude and preliminary' (2005a, p. 546). The scoring procedure is somewhat laborious and Keyes (Personal communication, 25 September 2007) has indicated that he, therefore, prefers using the simplified 14-item short form that he has developed subsequently. The short form could be useful in situations where participants' time is a concern and, after appropriate validation, perhaps even more useful in an organisational context than the long form.

Even though cross-validation is required, the general purport of the present findings is that the concept of psychosocial health, as reflected by Keyes's questionnaire, tends to have an effect on personal and organisational orientations such as those that were represented in the present study. To the extent that the findings suggest further study, they suggest serious involvement of industrial/organisational psychologists in psychological and social health considerations of organisation members too.

\section{REFERENCES}

Allen, N.J., \& Meyer, J.P. (1990). The measurement and antecedents of affective, continuance and normative commitment to the organization. Journal of Occupational Psychology, 63(1), 1-18.

Antonovsky, A. (1979). Health, stress, and coping: New perspectives on mental and physical well-being. San Francisco: Jossey-Bass.

Antonovsky, A. (1987). Unraveling the mystery of health: How people manage stress and stay well. San Francisco: Jossey-Bass.

Bandura, A. (1977). Self-efficacy: Toward a unifying theory of behavioral change. Psychological Review, 84(2), 191-215.

Bateman, T.S., \& Crant, J.M. (1993). The proactive component of organizational behavior: A measure and correlates. Journal of Organizational Behavior, 14(2), 103-118.

Clark, L.A., \& Watson, D. (1995). Constructing validity: Issues in objective scale development. Psychological Assessment, 7(3), 309-319.

Cohen, J. (1988). Statistical power analysis for the behavioral sciences. (2nd edn.). Hillsdale: Erlbaum.
Crant, J.M. (2000). Proactive behavior in organizations. Journal of Management, 26(3), 435-462.

Eisenberger, R., Cummings, J., Armeli, S., \& Lynch, P. (1997) Perceived organizational support, discretionary treatment, and job satisfaction. Journal of Applied Psychology, 82(5), 812820.

Hackett, R.D., Bycio, P., \& Hausdorf, P.A. (1994). Further assessment of Meyer and Allen's (1991) three-component model of organizational commitment. Journal of Applied Psychology, 79(1), 15-23.

Iverson, R.D., \& Buttigieg, D.M. (1999). Affective, normative and continuance commitment: Can the "right kind" of commitment be managed? Journal of Management Studies, 36(3), 307-333.

Jones, G.R. (1986). Socialization tactics, self-efficacy, and newcomers' adjustments to organizations. Academy of Management Journal, 29(2), 262-279.

Keyes, C.L.M. (1998). Social well-being. Social Psychology Quarterly, 61(2), 121-140.

Keyes, C.L.M. (2002). The mental health continuum: From languishing to flourishing in life. Journal of Health and Social Research, 43(2), 207-222.

Keyes, C.L.M. (2003). Complete mental health: An agenda for the 21st century. In C.L.M. Keyes \& J. Haidt (Eds.), Flourishing: Positive psychology and the life well-lived (pp. 293-312). Washington DC: American Psychological Association.

Keyes, C.L.M. (2005a). Mental illness and/or mental health? Investigating axioms of the complete state model of health. Journal of Consulting and Clinical Psychology, 73(3), 539-548.

Keyes, C.L.M. (2005b). The subjective well-being of America's youth: Toward a comprehensive assessment. Adolescent $\mathcal{E}$ Family Health, 4(1), 3-11.

Keyes, C.L.M. (2007). Promoting and protecting mental health as flourishing: A complementary strategy for improving national mental health. American Psychologist, 62, 95-108.

Keyes, C.L.M., \& Magyar-Moe, J. (2003). The measurement and utility of adult subjective well-being. In S.J. Lopez \& C.R. Snyder (Eds.), Positive psychological assessment (pp. 411-425). Washington DC: American Psychological Association.

Keyes, C.L.M., Wissing, M., Potgieter, J.P., Temane, M., Kruger, A., \& Van Rooy, S. (2008). Evaluation of the Mental Health Continuum - Short Form (MHC-SF) in Setswana-speaking South Africans. Clinical Psychology and Psychotherapy, 15(3), 181-192.

Kohn, M.L., \& Schooler, C. (1982). Job conditions and personality: A longitudinal assessment of their longitudinal effects. American Sociological Review, 87(6), 1257-1286.

Lynch, P.D., Eisenberger, R., \& Armeli, S. (1999). Perceived organizational support: Inferior versus superior performance by wary employees. Journal of Applied Psychology, 84(4), 467483.

McGee, G.W., \& Ford, R.C. (1987). Two (or more?) dimensions of organizational commitment: Reexamination of the affective and continuance commitment scales. Journal of Applied Psychology, 72(4), 638-642.

McMillan, E. (2004). Complexity, organizations and change London: Routledge.

Oreg, S. (2003). Resistance to change: Developing an individual differences measure. Journal of Applied Psychology, 88(4), 680-693.

Quinn, R.P., \& Sheppard, L.G. (1974). The 1972-1973 quality of employment survey. Ann Arbor: Institute of Social Research.

Robitschek, C., \& Keyes, C.L.M. (2009). Keyes's model of mental health with personal growth initiative as a parsimonious predictor. Journal of Counseling Psychology, 56(2), 321-329.

Ryff, C.D. (1989). Happiness is everything, or is it? Explorations on the meaning of psychological well-being. Journal of Personality and Social Psychology, 57(6), 1069-1081.

Ryff, C.D. (2001). Manual: Scales of psychological well-being. Madison: University of Wisconsin.

Ryff, C.D., \& Keyes, C.L.M. (1995). The structure of psychological well-being revisited. Journal of Personality and Social Psychology, 69(4), 719-727. 
Van Yperen, N.W., \& Janssen, O. (2002). Fatigued and dissatisfied or fatigued but satisfied? Goal orientations and responses

to high job demands. Academy of Management Journal, 45(6), 1161-1171. 